\title{
Modeling and Control by Multi-Model Approach of the Greenhouse Dynamical System with Multiple Time-delays
}

\author{
Marwa Hannachi ${ }^{1}$, Ikbel Bencheikh Ahmed ${ }^{2}$, Dhaou Soudani ${ }^{3}$ \\ Automatic Research Laboratory \\ BP 37, 1002 Tunis, Tunisia
}

\begin{abstract}
This paper presents the Internal Multi-Model Control IMMC for a multivariable discrete-time system with variable multiple delays. This work focus on the Greenhouse climate model as a multivariable time-delay system. In fact, the Greenhouse technology is an interesting subject for sustainable crop production in the regions of disadvantageous climatic conditions. In addition, high summer temperature is an important setback for successful greenhouse crop production throughout year. The main intent of this work is to present a new control of Greenhouse during summer months using the Internal Multi-Model approach. First, the plant and the model are discredited with the bilinear approximation and then they will be controlled with an Internal Multi-Model Control. The chosen system is modeled only in the summer season case. The simulation results prove the robustness of this Internal MultiModel Control to preserve stability system despite the incertitude of the chosen model and the extern disturbances.
\end{abstract}

Keywords-Variable time-delay; multivariable systems; greenhouse system; renewable energy; multi-model approach; commutation's technique; internal model control; discrete-time case; stability; disturbances; robustness

\section{INTRODUCTION}

Renewable energy sources are expected to find more applications in the daily life the next years. Among then their use in heating greenhouses is going to increase since many of renewable energies technologies are cost effective and environmentally friendly. Several studies for using greenhouses [1], [2] have been implemented and various commercial applications already exist [3]. In fact controllers are increasingly giving way to evolve this type of industrial processes. Therefore, the big problem that can present the greenhouses systems is the insufficient precision with its chosen model. The dilemma lies then in the fidelity of the model to the process.

To implement such control structures that ensure the desired objectives [4], modeling in the discrete time of analog systems is often required [5]. Indeed, it is found that the phenomena of delay appear naturally in the physical processes. And even if one of them doesn't contain intrinsic delays, they often appear in the control loop. Time-delay systems [6], [7] have an infinite dimensional system class frequently used for process modeling, which are systems that do not depend only on its current state but also on its previous state. This type of dynamic system is often present in practice as an example: renewable energy, hydraulic networks (the phenomenon of water transport), heat exchangers (distributed delay due to conduction in a tube) ... indeed the delay can cause instability [8], poor performance and difficulties [9] in process control design.

The diversity of control structures [10], [11], is linked in one hand to the objectives set and to the constraints on quality of the process and model on the other hand. In order to make a contribution to this axis of research, this work focuses on the Internal Multi-Model Control IMMC as a command structure known as a robust control [12]. The encouraging results of this control law in the mono variable continuous case encourage us to extend its application to multivariable discrete-time systems with the same number of inputs and outputs MIMO.

The realization of this control is based on a library of many local models describing the overall behavior of the system. Indeed, the Multi-model techniques are used to reduce the complexity of the system through its study in several operating points; in order to find several mathematical representations faithful to the dynamics of the system. These models [13] are called "Library", which will be used in a multi-model control use a certain metric that evaluates the degree of fidelity of each model and its influence in the control.

This metric is computed using several techniques to evaluate the degree of fidelity of each model to the actual behavior of the process to obtain a set of validities that will be used in a merge algorithm. This merge algorithm will use all the validities for the computation of the command thus making it possible to use the information coming from the library of the models and allows each model to intervene in the control of processes according to its degree of validity.

The objective of this work is the contribution to the application of the switching control technique in the validity of models in the development of the IMMC structure at discrete time, applied in order to ensure stability and maintenance of the physical system performances the "Greenhouse Climate Model", during the summer season, considered as a multivariable system with variable and multiple-time delays. 


\section{InTERnAl MUlti-MODEL CONTROL FOR Multivariable DiscRete System With MultiPle TIME-DELAYS}

The Internal Model Control IMC introduced by Garcia and Morari in the 1982 [22] and then in the 1985s [23], is a robust control structure [11], [12], currently used in several works [13], and [24]. It is presented as an alternative to the classic closed loop; it's useful at once to the process and its model. Their response is used to exact the difference on the set point. The error signal includes the influence of external disturbances as well as the modeling errors of the controlled system.

\section{A. IMC Structure of Multivariable Systems with Time Delays:}

\section{the Discrete Case}

In the IMC structure (described in Fig. 1), the controller is assumed to be the inverse of the model of the system to be controlled. Hence the need to study the problems related to this inversion since it is physically unfeasible in the majority of cases (problems of delays, non-minimal phase shift, or nonrelative non-zero degree...).

$C(z)$ is the IMC controller, $G(z)$ the process and $M(z)$ the process model which is an approximation of the plant $G(z)$. The transfer matrix of the process $G(z)$ with ' $n$ ' inputs and ' $n$ ' outputs (square system case) is given as follow:

$$
G(z)=\left[\begin{array}{cccc}
G_{11}(z) & G_{12}(z) & \cdots & G_{1 n}(z) \\
G_{21}(z) & G_{22}(z) & \cdots & G_{2 n}(z) \\
\vdots & \vdots & \ddots & \vdots \\
G_{n 1}(z) & G_{n 2}(z) & \cdots & G_{n n}(z)
\end{array}\right]
$$

The transfer function $G(z)$ is strictly proper and stable from the $i^{\text {th }}$ input to $j^{\text {th }}$ output.

Where :

$$
\begin{aligned}
G_{i j}(z) & =z^{-\tau_{i j}} \cdot F_{i j}(z) \\
& i, j=1, \cdots, 2 \text { and } \tau_{i j} \text { is the corresponding time delay. }
\end{aligned}
$$

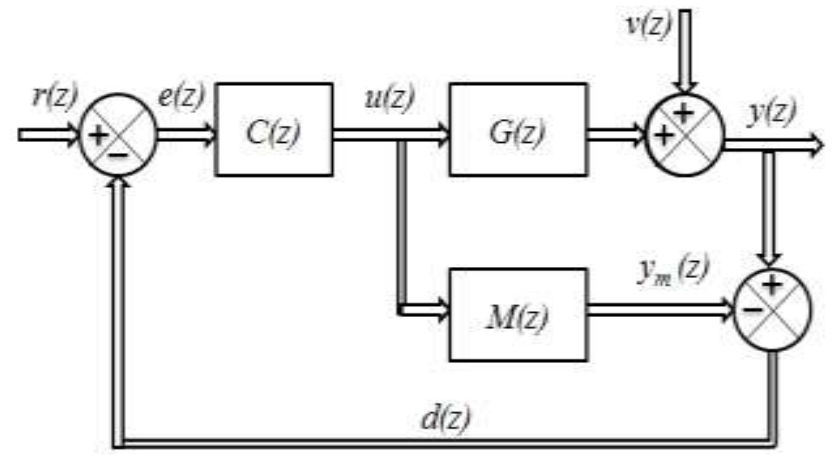

Fig 1. IMC Structure for Multivariable Discrete-Time System.

The structure of this approach is based on the elaboration of a corrector $C(z)$ obtained by inversion of the chosen model and whose product control signal $u(z)$ is applied both to the system and its model such that the error of their responses $d(z)$ will be compared to the signal of reference. The signal $v(z)$ is the disturbance which attacks the output directly and $r(z)$ is the references that are compared to the outputs signal $y(z)$ to reduce the error:

$$
\begin{aligned}
& d(z)=y(z)-y_{M} \\
& =(G(z)-M(z)) u(z)+v(z) \\
& u(z)=(r(z)-d(z)) C(z)= \\
& (r(z)-v(z)-(G(z)-M(z)) u(z)) C(z) \\
& u(z)=\left(I_{n}+C(z)(G(z)-M(z))\right)^{-1} C(z) r(z) \\
& +\left(I_{n}+C(z)(G(z)-M(z))\right)^{-1} C(z) v(z) \\
& y(z)=\left(I_{n}+C(z)(G(z)-M(z))\right)^{-1} C(z) G(z) r(z) \\
& +\left(I_{n}+C(z)(G(z)-M(z))\right)^{-1}\left(I_{n}-C(z) M(z)\right) v(z)
\end{aligned}
$$

$n$ : the number of inputs and outputs of the system

$$
I_{n}: \text { the identity matrix of order } n \text {. }
$$

\section{B. Stability Analysis}

The IMC controller is obtained by applying the proposed inversion method [24]. The generalized controller design regulator gives the matrix transfer $C(z)$ as following:

$$
C(z)=A_{r} \times\left(I_{n}+A_{r} M(z)\right)^{-1}
$$

$A_{r}$ is a square matrix gain, which coefficients are chosen to ensure the inversion of model to ensure the realization of the regulator and the stability of the closed loop system.

The stability of the proposed structure depends on the stability of the process to be controlled, the model and the proposed regulator which must be stable in open loop.

To simplify our study, $A_{r}$ is chosen as the following form:

$$
A_{r}=\alpha \times I_{n}
$$

with $\alpha \in \square^{+}$. For such choice of $A_{r}$ and if $\alpha$ is sufficiently high, $A_{r}^{-1}$ become sufficiently low which makes possible:

$$
\begin{aligned}
& I_{n} \times\left(A_{r}^{-1}+M(z)\right)^{-1} \approx I_{n} \times M^{-1}(z) \\
& C(z) \approx M^{-1}(z)
\end{aligned}
$$

The expression of the command become as follows:

$$
\begin{aligned}
& u(z)=I_{n}+\left(I_{n}+A_{r} M(z)\right)^{-1} A_{r}(G(z)-M(z))^{-1} \\
& \left(I_{n}+A_{r} M(z)\right)^{-1} A_{r}(r(z)-v(z)) \\
& y(z)=y_{r}(z) r(z)+y_{v}(z) v(z)
\end{aligned}
$$

Such that: 
$y_{r}(z)=G(z)\left[I_{n}+\left(I_{n}+A_{r} M(z)\right)\right]^{-1}$

$A_{r}(G(z)-M(z))^{-1}\left(I_{n}+A_{r} M(z)\right)^{-1} A_{r}$

$y_{v}(z)=I_{n}-G(z)\left[I_{n}+\left(I_{n}+A_{r} M(z)\right)\right]^{-1}$

$A_{r}(G(z)-M(z))^{-1}\left(I_{n}+A_{r} M(z)\right)^{-1} A_{r}$

If the process isn't submitted to any disturbance $v(z)=0$ and in the perfect modeling case $M(z)=G(z)$, so the expression of the output is reduced to the following equation:

$y(z)=G(z)\left[I_{n}+A_{r} G(z)\right]^{-1} A_{r} r(z)$

\section{Precesion Analysis}

The matrix of the static gains of the regulator $C(z=1)$ can be expressed according to the static gain matrix $M(z=1)$ of the system. It's defined with the following expression:

$C(z=1)=A_{r}\left(I_{n}+A_{r} M(z=1)\right)^{-1}$

In order to ensure the precision of the system, it is necessary to check that:

$C(1)=I_{n} \times M^{-1}(1)$

In this case, we can affirm the regulator stability to ensure a perfect continuation of the set points independently of any external disturbance. The general controller design with gain for precision $A p$ provides the following matrix:

$A_{p}=\left(I_{n}+A_{r} M(1)\right) \times\left(A_{r} M(1)\right)^{-1}$
$A_{p}$ a matrix, whose coefficients are chosen to ensure precision in the certain case of dynamical systems as which contained time delays.

$A_{p}$ is used to intended to compensate static errors in the multivariable system, while $A_{r}$ is chosen to ensure the stability to reach the inverse model.

\section{Multi-Model COMMAND FOR TIME-DELAY SYSTEM: COMMUTATION OF PARTIAL CONTROLS}

The rule of this technique is based on the selection of the model that is nearer to the process. The selection of the model is the result obtained by calculating the errors between the answers of the models and those of the system. After validating the model, the answer corresponding corrector is applied for process control and applied models.

The association of the Internal Model Controller design [24] and [25] and Multi-Model approach [13], [14], [15], [16], [17] and [27] resume the IMMC design; the implementation of this technique requires the application of the control signal for the system having variable and/or multiple time-delays chosen models $M_{1}(z) \cdots M_{q}(z)$.

The validity coefficient $\Gamma_{i}$, to evaluate the command, permits the selection of one of the associated controllers $C_{1}(z) \cdots C_{q}(z)$ which receives the difference between the reference and the outputs of the used models to minimize the errors. In fact, the validity coefficient is calculated by realizing the difference between the process outputs $y(z)$ and its models $y_{1}(z) \cdots y_{q}(z)$ then the model that has the minimum difference is applied to the command admitting its index to the coefficient's validity [14], [18].

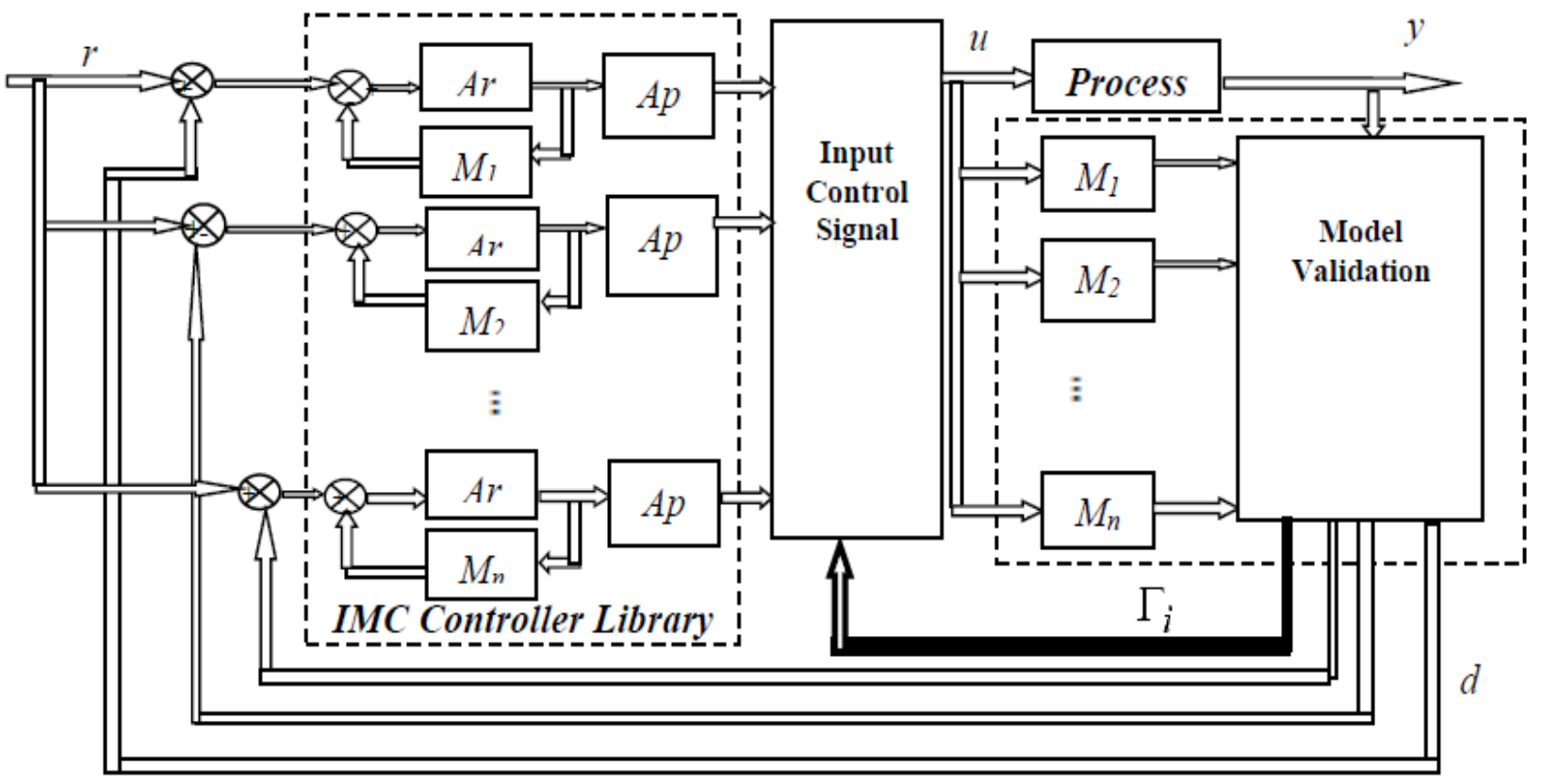

Fig 2. IMMC Structure for Multivariable Time-Delay System. 
After validate the perfect model [16], [17], (the nearest model to the system), the output of the corresponding regulator assumed as the inverse of the chosen model is applied as the control of the process and its different models [21] and [26]. The minimum difference $d_{i j}$ corresponding to validate the best model used in the calculation of the control law:

$d_{i j}(z)=y_{i}(z)-\tilde{y}(z), \quad i=1, \cdots, n$

To validate the model that describes the best dynamic behavior, we define coefficients $f_{i j}(z)$ that express the lowest error between the process and the chosen models:

$\mathrm{E}_{i}=\sum_{j=1}^{n}\left\|y_{i}(k)-\tilde{y}_{i j}\right\| \quad i=1 \ldots n$

Once the best model, is validated, the next step is to calculate the switching control law applied to the system. Partial commands for each model are calculated by applying the methods of inversion of the linear models detailed in the previous section. They constitute the library of inverted models. The Proposed structure IMMC for multivariable timedelays system is described in Fig. 2.

\section{CASE STUdY}

Greenhouse technology is an interesting process in the agriculture production technology that integrates market driven quality parameters with production system profits. In fact cultivation of crops in greenhouse is increasing from high altitude and temperate regions to the warmer regions of tropics and subtropics. Although, greenhouse protects crops from external bad weather, high temperature and humidity during summer months cause adverse effect on crop production in tropical region [2], [3]. The input/output scheme of the greenhouse model is presented by Fig. 3 .

Therefore, in such regions, reduction of air temperature inside the greenhouse or the regulation of temperature closer to the ambient temperature during summer is necessary for successful crop production [1], [2], and [3].

It can be summarized by the functional block diagram presented in the following design.

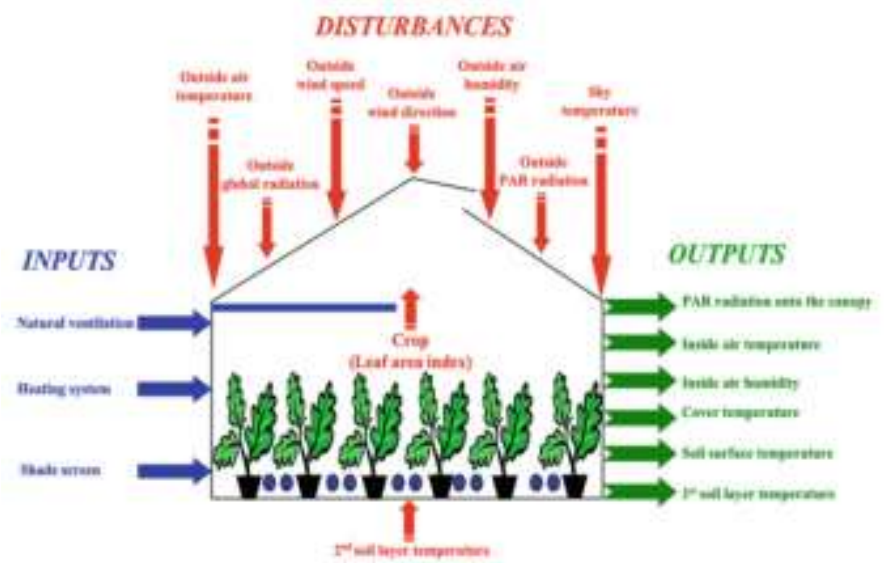

Fig 3. Inputs-Outputs Scheme of Climate Dynamic Greenhouse Models.

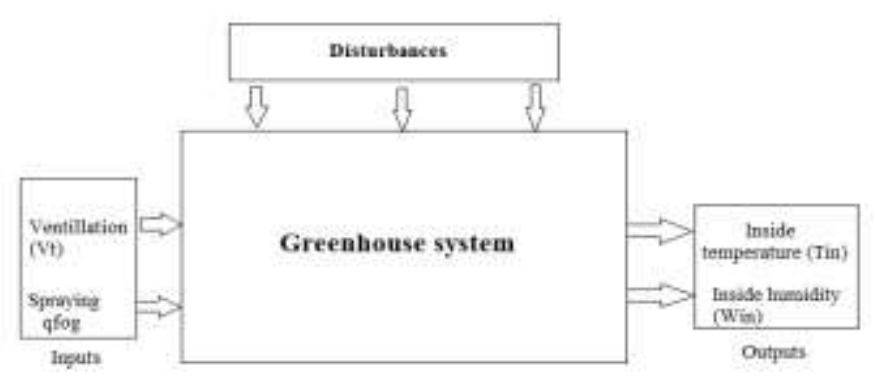

Fig 4. Greenhouse Climate Dynamic Model (Summer Operations).

TABLE I. Greenhouse Climate Model Parameters

\begin{tabular}{|l|l|}
\hline Tin $(t)$ & the indoor air temperature $\left({ }^{\circ} \mathrm{C}\right)$ \\
\hline $\mathrm{T}_{\text {out }}(\mathrm{t})$ & the outdoor temperature $\left({ }^{\circ} \mathrm{C}\right)$ \\
\hline$\rho$ & the air density $\left(\mathrm{kgm}^{-3}\right)$ \\
\hline$C \rho$ & the specific heat of air $(\mathrm{J} /(\mathrm{kgK}))$ \\
\hline $\mathrm{V}$ & the greenhouse volume $(\mathrm{m} 3)$ \\
\hline $\mathrm{W}_{\text {in }}$ & the interior humidity ratios (water vapor mass of dry air, in $\left.\mathrm{gm}^{-3}\right)$ \\
\hline $\mathrm{S}$ & the intercepted solar radiant energy $\left(\mathrm{Wm}^{-2}\right)$ \\
\hline$\chi$ & the latent heat of vaporization $\left(\mathrm{Jg}^{-1}\right)$ \\
\hline$\dot{V}(t)$ & the ventilation rate $\left(\mathrm{m}^{-1} \mathrm{~s}\right)$ \\
\hline $\mathrm{Oh}$ & $\begin{array}{l}\text { the overall heat transfer coefficient } \\
(\text { W/ }(\mathrm{m} 2 \mathrm{~K}))\end{array}$ \\
\hline $\mathrm{q}_{\text {fog }}$ & $\begin{array}{l}\text { the water capacity of the fog system }(\text { water vapor mass per } \\
\left.\text { second, in gs }{ }^{-1}\right)\end{array}$ \\
\hline $\mathrm{Ah}$ & the heat transfer surface area $\left(\mathrm{m}^{2}\right)$, \\
\hline $\begin{array}{l}\mathrm{E}\left(\mathrm{S}_{\mathrm{i}}(\mathrm{t}),\right. \\
\left.\mathrm{W}_{\text {in }}(\mathrm{t})\right)\end{array}$ & the evaporate transpiration rate of the plants $\left(\mathrm{gs}^{-1}\right)$ \\
\hline
\end{tabular}

This simplified model, based on energy and mass balance inside the greenhouse, contains two linear differential equations describing the latent and sensible heat, and the water vapor balance that are the controlled variables. To simplify the model, only primary disturbances are considered: outside temperature and humidity, and solar radiation. The greenhouse climate model can be used as a multi-season model, in this work, we interested only to the summer operations where the heater element is neglected. The greenhouse climate model is described by Fig. 4 .

The greenhouse model parameters are cited in Table 1.

The two manipulated inputs are the ventilation $\dot{V}(t)$ and the water capacity of the fog system $q_{\mathrm{fog}}$. The differential equations that govern sensible heat and water vapor balances inside the greenhouse volume are given by:

$$
\begin{aligned}
& \frac{d \operatorname{Tin}(t)}{d t}=\frac{1}{\rho C_{\rho} V}[S(t)-\chi q f o g(t)]-\frac{\dot{V}(t)}{V} \\
& {\left[T_{\text {in }}(t)-T_{\text {out }}(t)\right]-\frac{O h A h}{\rho C_{\rho} V}\left[T_{\text {in }}(t)-T_{\text {out }}(t)\right]} \\
& \frac{d W_{\text {in }}(t)}{d t}=\frac{1}{\rho V} q f o g(t)+\frac{1}{\rho V} E\left(S(t), W_{\text {in }}(t)\right) \\
& -\frac{\dot{V}(t)}{\rho V}\left[W_{\text {in }}(t)-W_{\text {out }}(t)\right]
\end{aligned}
$$


$E\left(S(t), W_{\text {in }}(t)\right)=\beta \frac{S(t)}{\chi}-\alpha W_{\text {in }}(t)$

$\beta=0.1249 ; \alpha=0$

$\beta$ is the coefficient accounting for shading and leaf area index, and $\alpha$ is the coefficient accounting for thermodynamic constants and other factors affecting evaporate transpiration.

\section{A. Greenhouse's Modeling and Identification}

At first time the equations (16) and (17) are derivated to determine the equilibrium point, and the constants environmental conditions are $(\bar{S}, \bar{T}$ out $, \bar{V}, \bar{q} f o g)$, the initial values are expressed by the following equations:

$$
\begin{aligned}
& T_{\text {in }}(0)=\frac{1}{\rho C \rho \bar{V}+O h A h}[\bar{S}-\chi \bar{q} f o g]+\bar{T}_{\text {out }} \\
& W_{\text {in }}(0)=\frac{1}{\bar{V}+\alpha}\left[\beta \frac{\bar{S}}{\chi}+\bar{q} f o g+\bar{W}_{\text {out }} \bar{V}\right]
\end{aligned}
$$

The greenhouse system considered in this work have different delays, these delays are considered as $\theta q T=100 \mathrm{~s}$ (dead time between qfog and $T_{i n}$ ), $\theta q W=180 \mathrm{~s}$ (dead time between qfog and Win ), $\theta \boldsymbol{v} T=90 \mathrm{~s}$ (dead time between $\dot{V}(t)$ and Tin ), and $\theta w T=220 s$ (dead time between $\dot{V}(t)$ and Win ), The values considered in the simulation test are shown in Table 2.

TABLE II. VARIABLE VALUES

\begin{tabular}{|l|l|l|l|}
\hline Variable & Value & Variable & Value \\
\hline V & $4000 \mathrm{~m} 3$ & C & $1006 \mathrm{~J} /(\mathrm{kgK})$ \\
\hline OhAh & $25,000 \mathrm{~W} / \mathrm{K}$ & $V^{\prime} t$ & $10 \mathrm{~m} 3 / \mathrm{s}$ \\
\hline$\rho$ & $1.2 \mathrm{~kg} / \mathrm{m} 3$ & $\chi$ & $2257 \mathrm{~J} / \mathrm{g}$ \\
\hline qfog & $18 \mathrm{~g} / \mathrm{s}$ & qfogMAX & $150 \mathrm{~g} / \mathrm{s}$ \\
\hline$S$ & $300 \mathrm{~W} / \mathrm{m} 2$ & Tout & $25 \circ \mathrm{C}$ \\
\hline Wout & $4 \mathrm{~g} / \mathrm{m} 3$ & $\dot{V}_{\text {MAX }}$ & $23 \mathrm{~m} / \mathrm{s}$ \\
\hline
\end{tabular}

In this work, we present the results obtained by simulations of a linear process and with an uncertain delay; controlled by the IMMC approach by applying the partial command switching in the calculation of the global command [19], [24] and [20], the considered process is presented by the transfer matrix as follows:

$G(s)=\left[\begin{array}{ll}G_{11} & G_{12} \\ G_{21} & G_{22}\end{array}\right]$

with

$G_{12}(s)=\frac{-0.05705}{140 s+1} e^{-(\tau+\delta \tau) s}$

$\tau+\delta \tau$ is uncertain and bounded delay as $\tau+\delta \tau \leq 104 s$ such as $\tau=101 s$ and $\delta \tau$ unknown.
This unknown delay $\tau+\delta \tau$ will be estimated by four delays $\tau_{i}$ such that $\tau_{i}=\tau+\delta \tau_{i}$ for the following delays: $\tau_{1}=101 s ; \tau_{2}=160 s ; \tau_{3}=200 s$ and $\tau_{4}=250 s$ which gives us the following four delay models for the transfer function $G_{12}(s)$ :

$$
\begin{array}{ll}
G_{12}^{1}=\frac{-0.05705}{140 s+1} e^{-101 s} & G_{12}^{2}=\frac{-0.05705}{140 s+1} e^{-150 s} \\
G_{12}^{3}=\frac{-0.05705}{140 s+1} e^{-200 s} & G_{12}^{4}=\frac{-0.05705}{140 s+1} e^{-250 s} \\
G_{11}=\frac{-0.1806}{150 s+1} e^{-89.5 s} & G_{21}=\frac{-0.8357}{580 s+1} e^{-220 s} \\
G_{22}=\frac{-0.134}{610 s+1} e^{-180 s} &
\end{array}
$$

The calculation of the $I M C$ regulators according to the structure of the corrector detailed in Section II from the models given above will be developed based on the partial commands.

\section{B. IMMC for the Greenhouse: Commutation Technique}

The transfer matrix of the discrete-time system is sampled with the bilinear approximation for a sampling period $T=20 s$ and the desired reference vectors Tindes $=25 C^{\circ}$, Windes $=8 \mathrm{gm}^{-}{ }^{3}$; initial conditions $\operatorname{Tin}(0)=39 \quad C^{\circ}$, and $\operatorname{Win}(0)=2 \mathrm{gm}^{-}{ }^{3}$. Each sampled model $M_{i, i=1, \cdots, 4}$ is defined as follow:

$M_{1}=\left[\begin{array}{ll}\frac{-0.0012 z-0.0012}{z+0.9987} z^{-4} & \frac{-0.0004 z-0.0004}{z+0.9986} z^{-5} \\ \frac{-0.0014 z-0.0014}{z+0.9997} z^{-11} & \frac{-0.0002 z-0.0002}{z+0.9997} z^{-9}\end{array}\right]$
$M_{2}=\left[\begin{array}{ll}\frac{-0.0012 z-0.0012}{z+0.9987} z^{-4} & \frac{-0.0004 z-0.0004}{z+0.9986} z^{-8} \\ \frac{-0.0014 z-0.0014}{z+0.9997} z^{-11} & \frac{-0.0002 z-0.0002}{z+0.9997} z^{-9}\end{array}\right]$

$M_{3}=\left[\begin{array}{ll}\frac{-0.0012 z-0.0012}{z+0.9987} z^{-4} & \frac{-0.0004 z-0.0004}{z+0.9986} z^{-10} \\ \frac{-0.0014 z-0.0014}{z+0.9997} z^{-11} & \frac{-0.0002 z-0.0002}{z+0.9997} z^{-9}\end{array}\right]$

$M_{4}=\left[\begin{array}{ll}\frac{-0.0012 z-0.0012}{z+0.9987} z^{-4} & \frac{-0.0004 z-0.0004}{z+0.9986} z^{-13} \\ \frac{-0.0014 z-0.0014}{z+0.9997} z^{-11} & \frac{-0.0002 z-0.0002}{z+0.9997} z^{-9}\end{array}\right]$

The gain's matrix are given as: $A_{r}=0.01 \times I_{2}$ and

$A_{p}=\left[\begin{array}{cc}6.8022 * 10^{5} & -1.262 * 10^{6} \\ -4.4636 * 10^{6} & 3.7282 * 10^{6}\end{array}\right]$

\section{Simulations and Results}

The step response of the system is figured in Fig. 5. 


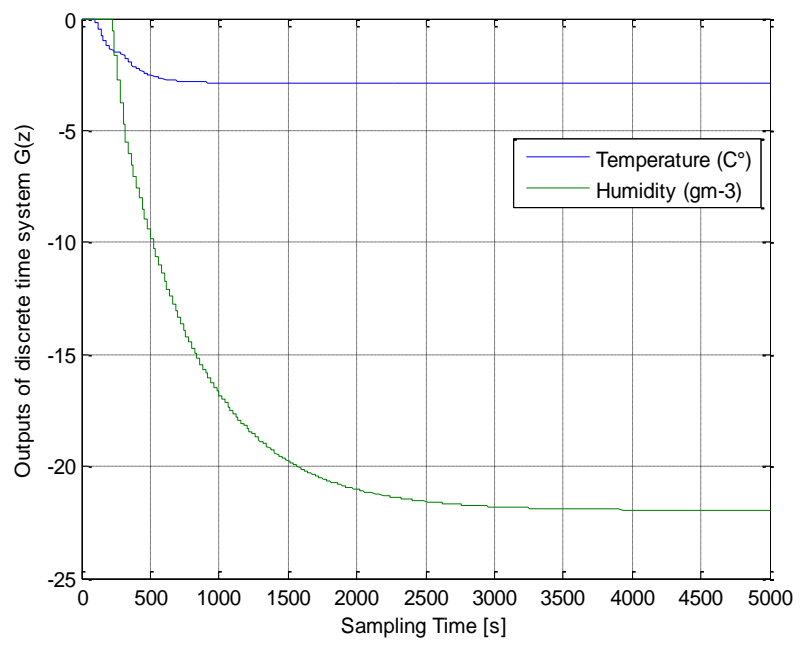

Fig 5. Step Response of the Discrete-Time System G(z), $\operatorname{Win}(0)=8 \mathrm{gm}^{-3}$, $\operatorname{Tin}(0)=39 \mathrm{C}^{\circ}, T=20 \mathrm{~s}$.

The IMMC is considered in the commutation of partial controls case for different scenarios, are shown in Fig. 6, 7, 8 and 9 .

a) Nominal Case

The results of simulations of the looped system illustrated in Fig. 5 and Fig. 6 show stable, fast and sufficiently precise responses of the indoor air temperature $T_{i n}\left({ }^{\circ} \mathrm{C}\right)$ and the interior humidity ratios $W_{\text {in }}\left(\mathrm{gm}^{-3}\right)$.

The MIMO system responses obtained by applying the switching technique to models with multiple delays confirm the properties of stability, speed and accuracy despite modelling uncertainties, sampled approximations and delay variations.

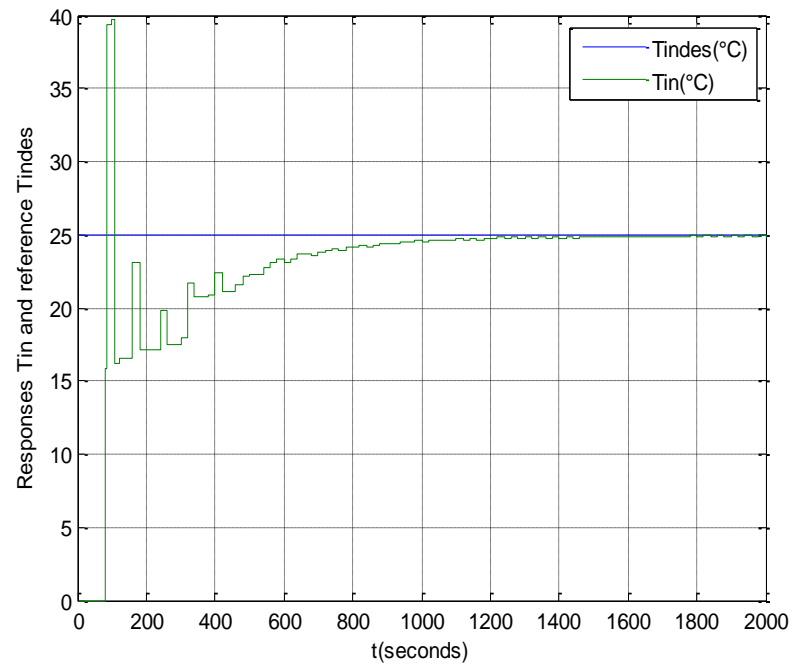

Fig 6. Responses Ti and Tides $=25 C^{\circ}$ of closed loop system's regulator $\operatorname{Tin}(0)=39 \mathrm{C}^{\circ}, T=20 \mathrm{~s}$.

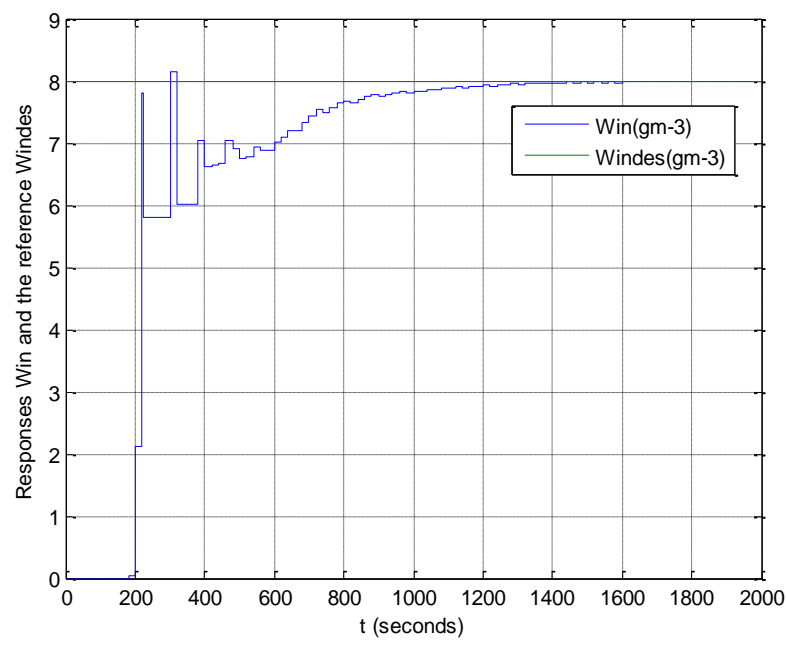

Fig 7. Responses Win and $W_{\text {indes }}=8 \mathrm{gm}^{3}$ of closed loop, system's regulator

$$
W_{\text {in }}(0)=2.2 \mathrm{gm}^{-3} ; \mathrm{T}=20 \mathrm{~s} \text {. }
$$

\section{b) Regulator's Robustness: External Disturbances}

In a position to test the effectiveness of our approach is envisaged in this scenario to study the rejection of external perturbations property applied to the system considering two vectors disturbances.

The disturbances envisaged are applied as well to the temperature as to the humidity signal produced respectively at $t$ $=1400 \mathrm{~s}$ and $t=1000 \mathrm{~s}$ and constant amplitude $5\left({ }^{\circ} \mathrm{C}\right)$ and $1\left(\mathrm{gm}^{-3}\right)$. The indoor air temperature Tin and the interior humidity ratios Win of Greenhouse obtained by the partial switching approach are illustrated respectively in Fig. 7 and 8. In the face of these disturbances applied directly to the responses of the system, we obtain a continuation of the references for the looped system.

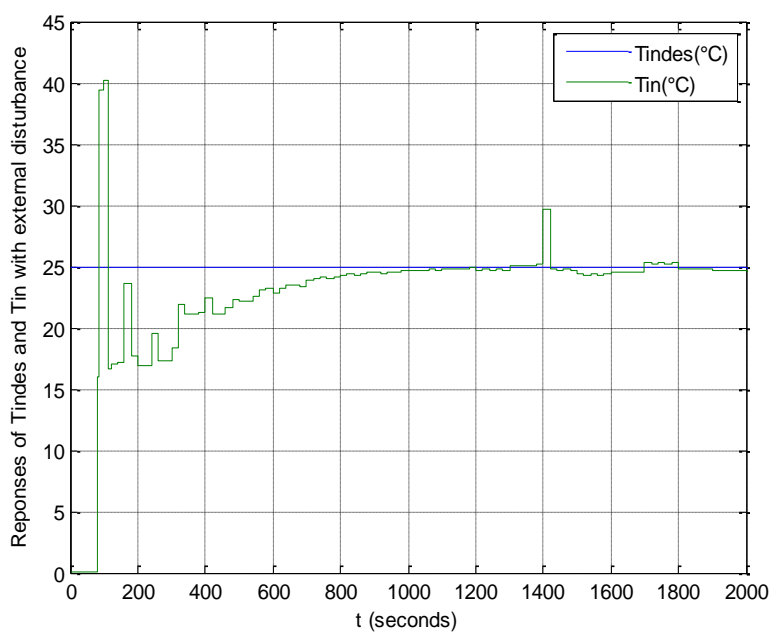

Fig 8. Temperature System's Outputs with External Disturbance at t=1400s. 


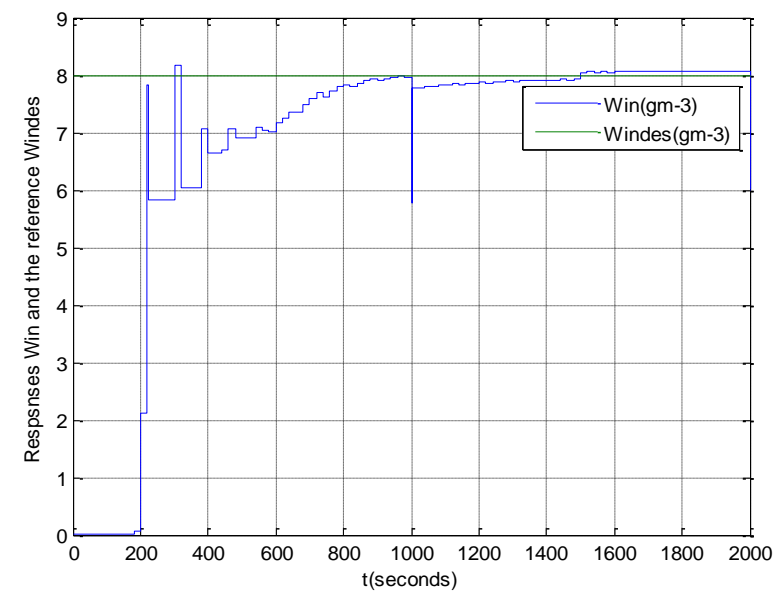

Fig 9. Interior Humidity Ratios System's Outputs with External Disturbance at $t=1000$ s.

It is clear that the models outputs are close to the system output, leading to the control signal variation. It can be seen also that the plant outputs reach perfectly the reference inputs as compared to other models outputs. So we can see clearly that the proposed controller which combines Multi-Model and internal model control presents satisfactory results. The simulation results prove the effectiveness of this approach to preserve the performances of the system.

\section{CONClusion}

This paper addresses a Multi-model control for multiple time-delay system modelled in the discrete case. The process was, firstly, designed then sampled with the bilinear method and secondly, implemented into internal multi-model control IMMC. An application of a greenhouse at summer case as a MIMO (two inputs - two outputs) time-delays system is proposed to test the effectiveness of the control. The simulation results show the proposed approach capability to preserve the system stability and performances although the chosen model, varying time-delay indeed the preserving of the rejection of the external disturbances. Future work focuses on internal multimodel control for nonlinear systems to preserve again the effectiveness of this approach.

\section{REFERENCES}

[1] Z. Pek, L. Hayles, "The effect of daily temperature on truss flowering rate of ornamental crops", Journal of Science of Food and Agriculture 84 (13) 1671-1674, 2004.

[2] V.P. Sethi, S.K. Sharma, "Experimental and economic study of a greenhouse thermal control system using aquifer water", Energy Conversion and Management 48 (1), 306-319, 2007.

[3] K.S. Kumar, K.N. Tiwari, Madan K. Jha , "Design and technology for greenhouse cooling in tropical and subtropical regions: A review", Indian Institute of Technology, Kharagpur 721302, India.

[4] T. Hongfeng, Z. Hua, Y. Huizhong and X. Jie, "Iterative learning control for nonlinear time-delay repetitive systems with arbitrary initial value", 33rd Chinese Control Conference (CCC), July 2014.

[5] P. Richard, "Time-delay systems: An overview of some recent advances and open problems", Automatica, 2003.
[6] M. De-Yuan, J. Ying-Min, D. Jun-Ping and Yu Fa-Shan, "Stability Analysis of Continuous-time Iterative Learning Control Systems with Multiple State Delays", ACTA AUTOMATICA SINICA 36(5), May 2010.

[7] M. Morari, Zafiriou E, "Robust Process Control", Ed. Prentice Hall, Englewood cliffs, N.J., 1989.

[8] M. Chadli., "Stabilité et commande de systèmes décrits par des multimodèles". Thèse de doctorat, Institut National plytechnique de Lorraine, 2002.

[9] A. M. Nagy., "Analyse et synthèse de multimodèles pour le diagnostic". Application à une station d'épuration'. Thèse de doctorat, Institut National plytechnique de Lorraine, 2010.

[10] Boling J.M. , Seborg D. E. and Hespanha J. P. "Multi-model control of a simulated ph neutralization process". IFAC, 16, 2005.

[11] Lupu C. , Borne P. and Popescu D., "Multi-model adaptive control systems". CEAI, 10, 2008.

[12] D. Soudani, M. Naceur, K. Ben Saad and M. Benrejeb., "On an Internal Multimodal Control for non-linear systems: a comparative study"., International Journal of Modeling, Identification and Control, JMIC, 5, 2008.

[13] N. Touati, D. Soudani, M. Naceur and M. Benrejeb., "Internal multimodel control for multivariable nonlinear systems". The 3rd International Conference on Systems and Control, ICSC, 2013.

[14] M. De-Yuan, J. Ying-Min, D. Jun-Ping and Yu Fa-Shan., "Stability Analysis of Continuous-time Iterative Learning Control Systems with Multiple State Delays", ACTA AUTOMATICA SINICA 36(5), May 2010.

[15] J. Chen, B. Zhang and X. Qi, "A new control method for MIMO first order time delay non-square systems". Journal of Process Control, 2011.

[16] J. Jian, Y. Min and L. Quan., "Generalized Synchronization of TimeDelayed Discrete Systems", Communications in Theoretical Physics, June 2009.

[17] D. Du, B. Jiang, "Actuator fault estimation and accommodation for switched systems with time delay: Discrete-time case", ISA Transactions, May 2016.

[18] Y. He, Q. G. Wang, L. Xie and C. Lin., "Further improvement of freeweighting matrices technique for systems with time-varying delay", IEEE Transactions on Automatic Control, 2007.

[19] Ch. Xu, B. Zhou and D. Guangren., "Delayed Output Feedback of Discrete-Time Time-Delay Systems with Applications to Spacecraft Rendezvous", IET Control Theory and Applications, January 2018.

[20] S. Dasgupta., "Kharitonov's theorem revisited". Systems and Control Letters, 11:381-384, 1988.

[21] F. Delmote., "Analyse multimodèle”. PhD Thesis, USTL, Lille, 1997.

[22] M. Morari and C.E. Garcia., "Internal Models Control 1", A Unifying Review and Some Results. Ind. Eng. Chem. process Des. Dev. vol. 21, pp. 403-411, 1982.

[23] C. E. Garcia and M. Morari., "Internal Model Control. 2. Design Procedure for Multivariable Systems,"Industrial. Engineering. Chemical. Process Design. Development. vol 24, pp 472, 1985.

[24] M. Hannachi, I., Ben Cheikh Ahmed and D., Soudani, "Singular Perturbed Uncertain Multivariable System controlled by Internal Model Control in Discrete-Time", 5th International Conference on Control and Signal Processing, CSP, Kairouan, 2017.

[25] I. Ben Cheikh Ahmed, D. Soudani, M. Naceur and M. Benrejeb., "Sur la commande stabilisante par modèle interne de systèmes échantillonné", JETA 2008.

[26] K. Kardous Z., "Sur la modélisation et la commande multimodèle des processus complexes et/ou incertains", PhD Thesis, USTL, in French, Décembre 2006.

[27] X. X. Liao, L. Q. Wang and P. Yu., "Stability of Dynamical Systems", London: Elsevier, 2007 